\title{
ADEQUAÇÃO DO ATLAS ESCOLAR DO ESTADO DE GOIÁS ÀS EXPECTATIVAS DE APRENDIZAGEM RELACIONADAS AO MUNICÍPIO: ESTUDO DE CASO PARA IPORÁ-GO
}

\author{
Thais Cristina Alves Borges ${ }^{(a)}$ Natália Martins Queiroz ${ }^{(a)}$ Diego Tarley Ferreira Nascimento ${ }^{(c)}$ \\ (a) Acadêmicas do curso de Geografia da da Universidade Estadual de Goiás - Campus Iporá, \\ nataliamartinsqueiroz@gmail.com; thais.ipora@gmail.com \\ (b) Professor do curso de Geografia da Universidade Estadual de Goiás - Campus Iporá, diego.tarley@ gmail.com
}

\section{EIXO: GEOGRAFIA FÍSICA: CURRÍCULO, FORMAÇÃO E PRÁTICAS DE ENSINO}

\begin{abstract}
Resumo
Os Atlas Escolares apresentam uma proposta mais ampla do que simplesmente os Atlas Geográficos, uma vez que propõem um trabalho conjunto de formação do aluno e do professor, por meio de uma linguagem gráfica e textual de conteúdos voltados às especificidades da realidade local. Apesar dos Atlas Escolares geralmente atenderem a escala municipal, foi pensada a elaboração do Atlas Geográfico Escolar do estado de Goiás. Assim, o presente trabalho tempo por objetivo fazer uma avaliação da adequação do Atlas Escolar do Estado de Goiás em atender as expectativas de aprendizagem referente ao município, tendo como estudo de caso o município de Iporá-GO. Segundo analises e discussões realizadas no presente trabalho, o Atlas Escolar do Estado de Goiás possui adequação para ser trabalhado também na escala municipal, haja vista atender parte das expectativas de aprendizagem para o município.
\end{abstract}

Palavras chave: Anos-padrão; Regime; Precipitação; Chuva; Climatologia.

\section{Introdução}

A concepção inicial dos Atlas Escolares ocorreu na Universidade Federal de Minas Gerais, sob a responsabilidade Le Sann (1983), que coordenou e elaborou atlas de alguns municípios mineiros, com o objetivo de contribuir com o processo de ensino-aprendizagem de Geografia nas séries iniciais do Ensino Fundamental. A metodologia utilizada para elaboração desses atlas difundiu-se e tornou-se peculiar no que diz respeito à Cartografia Escolar, especialmente no que diz respeito ao estudo do lugar e à formação de professores do Ensino Fundamental (OLIVEIRA, 1978; ALMEIDA E PASSINI, 1989; PASSINI, 1994; ALMEIDA, 1994, 2001, 2007; BUENO, 2008; LE SANN, 2009)..

Enquanto instrumento didático-pedagógico no processo de ensino-aprendizagem de Geografia, em diferentes níveis de ensino, os Atlas Escolares apresentam uma proposta mais ampla do que simplesmente os Atlas Geográficos, não se configurando apenas em uma coleção de mapas, uma vez que propõem um 


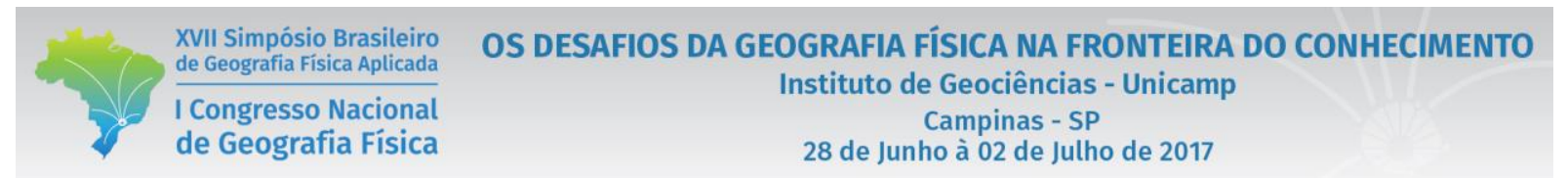

trabalho conjunto de formação do aluno e do professor, por meio de uma linguagem gráfica e textual de conteúdos adaptados ao nível de ensino a que se destina, bem como às especificidades da realidade local.

Diante da necessidade de um maior diálogo e construção de saberes geográficos referentes às características históricas, sociais, culturais, econômicas e físicas do estado de Goiás, feitas a partir de uma linguagem clara, objetiva e acessível, é que foi pensada a elaboração do Atlas Geográfico Escolar do estado de Goiás (SANTOS, NASCIMENTO, BUENO, 2016) - Figura 1. Maiores informações a respeito do processo de concepção e elaboração do Atlas Escolar de Goiás são apresentadas por Nascimento e Santos (2016).

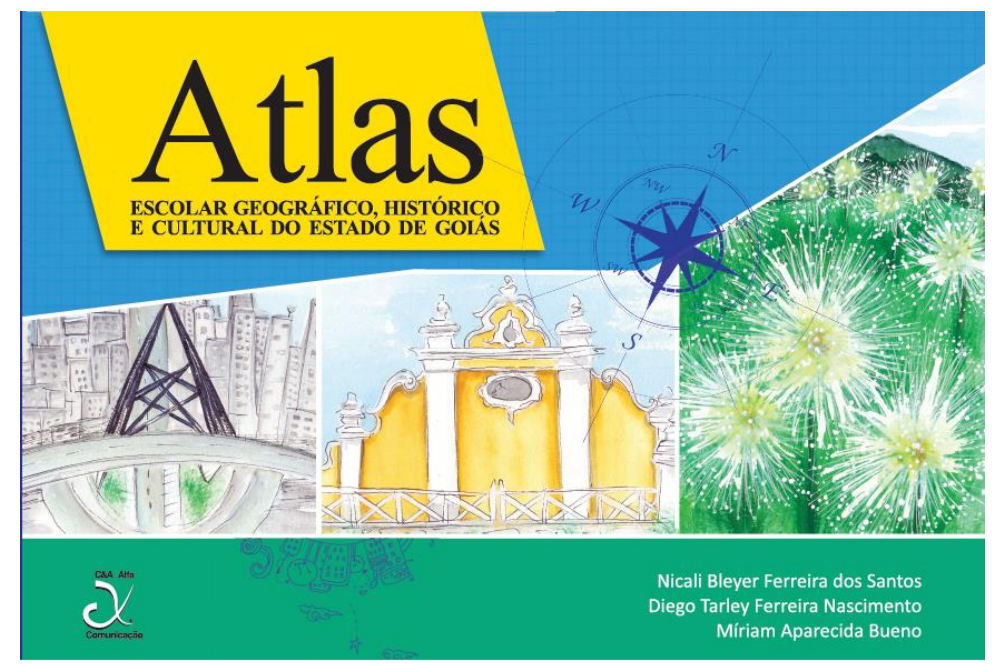

Figura 1 - Capa do Atlas Escolar Geográfico, Histórico e Cultural do Estado de Goiás.

Fonte: próprios autores, com base em Santos, Nascimento e Bueno (2016).

Contudo, apesar dos Atlas Escolares serem comumente desenvolvidos para abarcarem o estudo do local, na escala municipal, O Atlas Escolar do Estado de Goiás foi desenvolvido perante a escala estadual, voltado principalmente para o Ciclo II do Ensino Fundamental (5 ao $9^{\circ}$ ano).

Assim, o presente trabalho tempo por objetivo fazer uma avaliação preliminar da adequação do Atlas Escolar do Estado de Goiás em atender as expectativas de aprendizagem referente ao município, tendo como estudo de caso o município de Iporá-GO.

Para tanto, os procedimentos metodológicos se basearam no levantamento das expectativas de aprendizagem do ensino fundamental e médio referente ao município, sendo consultado o Currículo de Referência do Estado de Goiás. A etapa seguinte consistiu na análise se as expectativas são contempladas e na avaliação do trato das mesmas pelo Atlas.

\section{Resultados e Discussões}


O Quadro 1, na sequência, apresenta as expectativas de aprendizagem referentes à escala do município para o ensino fundamental e médio, conforme o Currículo de Referência do Estado de Goiás. Geralmente as expectativas de aprendizagem se referem a especificidades do lugar. No ensino fundamental, apenas os $5^{\circ}$ e $8^{\circ}$ anos, ao passo que no ensino médio, a $1^{\mathrm{a}}$ e $2^{\mathrm{a}}$ série, não apresentam expectativas relacionadas ao município.

\begin{tabular}{|c|c|}
\hline \multicolumn{2}{|r|}{ Ensino Fundamental } \\
\hline $\begin{array}{l}\stackrel{̊}{\Xi} \\
\stackrel{\Xi}{-}\end{array}$ & $\begin{array}{l}\text { - Identificar o próprio corpo como referencial de localização, no espaço e no tempo } \\
\text { percebendo-o como ponto de lateralidade e localização. } \\
\text { - Observar a paisagem local e seus elementos. } \\
\text { - Identificar aspectos naturais e culturais de onde vive. } \\
\text { - Identificar diferenças e semelhanças dentro de um grupo social. } \\
\text { - Relacionar o meio ambiente com as formas de vida estabelecidas. }\end{array}$ \\
\hline $\begin{array}{l}\stackrel{̊}{\Xi} \\
\stackrel{\Xi}{\sim} \\
\stackrel{1}{*}\end{array}$ & $\begin{array}{l}\text { - Localizar a escola geograficamente. } \\
\text { - Identificar as mudanças que ocorre na paisagem a partir da dinâmica da natureza (variação } \\
\text { da temperatura e ocorrência ou não de precipitação). } \\
\text { - Identificar percurso casa-escola- descrevendo paisagem natural e cultural. }\end{array}$ \\
\hline $\begin{array}{l}\stackrel{0}{\sigma} \\
\text { i } \\
\text { in }\end{array}$ & $\begin{array}{ll}- & \text { Identificar algumas formas de agressão ao meio ambiente. } \\
\text { - } & \text { Localizar no mapa do município o seu bairro. } \\
\text { - } & \text { Localizar no mapa do estado seu município. }\end{array}$ \\
\hline 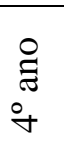 & $\begin{array}{ll}\text { - } & \text { Identificar as diferentes paisagens que compõem o município ( Natural e Cultural). } \\
\text { - } & \text { Identificar diferentes tipos de vegetação que compõem a paisagem do município. } \\
\text { - } & \text { Identificar no mapa limites entre os municípios vizinhos de seu próprio município. }\end{array}$ \\
\hline $\begin{array}{l}\stackrel{8}{\tilde{\Xi}} \\
\dot{0}\end{array}$ & $\begin{array}{l}\text { - } \text { Representar os espaços de vivencia em mapas mentais, croquis, plantas, maquetes } \\
\text { entre outros. } \\
\text { - } \\
\text { - } \\
\text { mapas. } \\
\text { - } \\
\text { de Geconvolver noções sobre divisas, limites e fronteiras entre os municípios de Goiás. } \\
\text { - } \quad \text { a sua imporer os principais rios, córregos, lagos e lagoas do seu município e do estado } \\
\text { outros }\end{array}$ \\
\hline 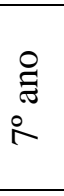 & $\begin{array}{l}\text { - } \quad \text { Reconhecer o processo de formação do território goiano e seus municípios. } \\
\text { - } \quad \text { Identificar os principais rios de Goiás e seu Município. } \\
\text { - } \quad \text { Perceber as relações e alterações que ocorrem nos ecossistemas e domínios } \\
\text { morfoclimaticos no estado de Goiás e seus municípios. }\end{array}$ \\
\hline $\begin{array}{l}\stackrel{8}{\Xi} \\
\stackrel{8}{a}\end{array}$ & $\begin{array}{l}\text { - Refletir sobre a organização do espaço em que vivemos. } \\
\text { - } \quad \text { Identificar, analisar e refletir sobre as questões ambientais, sociais e culturais } \\
\text { decorrentes do processo de globalização mundial e suas implicâncias no estado de Goiás e } \\
\text { em seus municípios. }\end{array}$ \\
\hline & Ensino Médio \\
\hline
\end{tabular}


- Localizar sua cidade, seu município em mapa, e percebê-lo com parte integrante do espaço goiano, brasileiro, identificando as características físiconaturais, histórico-culturais, econômicas, sociais e seus usos potenciais.

Quadro 1 - Expectativas de aprendizagem relacionadas ao município.

Fonte: próprios autores, segundo o Curriculo de Referência do Estado de Goiás.

Identificando, analisando e avaliando o conteúdo do Atlas Escolar de Goiás, percebe-se que para o primeiro e segundo ano do ensino fundamental as expectativas de aprendizagem não são atendidas pelo Atlas, por conta da especificidade de tais expectativas de aprendizagem e não capazes de serem atendidas num material desenvolvido à escala estadual.

Para o terceiro ano do ensino fundamental, algumas das expectativas de aprendizagem são capazes de serem trabalhadas com o uso do Atlas Escolar do Estado de Goiás, tais como: identificar as formas de agressão ao meio ambiente e localizar no mapa do estado o município do estudante, nesse caso, Iporá-GO. A respeito da primeira expectativa, o Atlas descreve e ilustra alguns problemas ambientais comuns no estado de Goiás, como queimadas, erosões, alagamentos e inundações.

Com relação às expectativas de aprendizagem para o quarto ano do ensino fundamental, apesar de o Atlas não retratar as paisagens e os tipos de vegetação do próprio município de Iporá, ele traz algumas ilustrações das paisagens naturais e artificiais do estado de Goiás, indicando as principais cobertura e uso do solo: pastagem, agricultura, área urbana e cobertura vegetal natural, além de apresentar as fitofisionomias do bioma cerrado (Figura 2). Ainda, a expectativa de aprendizagem a respeito dos limites entre o município do estudante com os municípios vizinhos aparecem no momento em que o Atlas demonstra a Região de Planejamento do Oeste Goiano, indicando os municípios, a população e a área territorial de cada um.

Para o sexto e sétimo ano do ensino fundamental, o Atlas atende a discussão e diferenciação dos conceitos de divisas, limites e fronteiras, representando a fronteira do Brasil com relação aos demais países da América do Sul; as divisas do estado de Goiás com relação as demais unidades federativas; e os limites entre os municípios goianos. Além dessa expectativa, o Atlas também apresenta os principais rios e lagos do estado de Goiás, indicando a importância dos corpos hídricos como vias de transportes, geração de energia, pesca, lazer entre outros.

Já voltado a terceira série do ensino médio, o Atlas é capaz de retratar e subsidiar discussões a respeito da diversidade cultural da sociedade goiana, trazendo conteúdos como as festas, a culinária, as músicas, os artistas, os mitos, as lendas e o modo de falar do habitante goiano. 


\section{Considerações Finais}

A Cartografia é considerada como a linguagem própria da Geografia, sendo responsável por orientar o estudo, concepção, produção e utilização de mapas e outras formas de comunicação que transmitam a localização, a distância e a orientação de objetos ou fenômenos e, quando bem elaborados, chegam a ser capazes de "revelar a Geografia" desses objetos e fenômenos.

É nesse anseio que são produzidos os Atlas Escolares, sejam nas escalas municipal, estadual ou nacional, os quais, por meio de mapas, gráficos, tabelas e textos, objetivam auxiliar o processo de ensinoaprendizagem do espaço local.

Mesmo sendo desenvolvidos em escala menores e com o intuito de atender series específicas do ensino fundamental e/ou médio, devido a falta de materiais didáticos que tragam dados e informações do espaço local, os Atlas Escolares podem ser importante instrumento de ensino. Esse foi o caso do Atlas Escolar do Estado de Goiás, que, segundo análises e discussões realizadas no presente trabalho, possui adequação para ser trabalhado também na escala municipal, haja vista atender parte das expectativas de aprendizagem para o município.

\section{REFERÊNCIAS}

ALMEIDA, R. D. Do desenho ao mapa: iniciação cartográfica na escola. São Paulo: Contexto, 2001.

. Cartografia Escolar. São Paulo: Contexto, 2007.

Uma proposta metodológica para a compreensão de mapas geográficos. São Paulo, Tese (Doutorado), Faculdade de Educação, Universidade de São Paulo, 1994. 289p.

; PASSINI, E. Y. Espaço geográfico: ensino e representação. São Paulo: Contexto, 1989.

BUENO, M. A. Atlas Escolares municipais e a possibilidade de formacão continuada de professores: um estudo de caso em Sena Madureira / AC. Campinas, SP, Tese (Doutorado), Instituto de Geociências, Universidade Estadual de Campinas, 2008.

LE SANN, J. G. Elaborando um atlas municipal. Belo Horizonte, 2009.

NASCIMENTO, D. T. F.; SANTOS, N. B. F. dos . ELABORAÇÃO DO ATLAS ESCOLAR DE GOIÁS. In: COLÓQUIO DE CARTOGRAFIA PARA ESCOLARES, 2016, Goiânia. Anais, 2016. p. 35-41

OLIVEIRA, L. de. Estudo metodológico e cognitivo do mapa. São Paulo: IGEOG-USP, 1978. (Série Teses e Monografias, 32). 


\begin{tabular}{|c|c|}
\hline $\begin{array}{l}\text { XVII Simpósio Brasileiro } \\
\text { de Geografia Fisica Aplicada } \\
\end{array}$ & $\begin{array}{l}\text { OS DESAFIOS DA GEOGRAFIA FÍSICA NA FRONTEIRA DO CONHECIMENTO } \\
\text { Instituto de Geociências - Unicamp }\end{array}$ \\
\hline $\begin{array}{l}\text { I Congresso Nacional } \\
\text { de Geografia Física }\end{array}$ & $\begin{array}{l}\text { Campinas - SP } \\
28 \text { de Junho à } 02 \text { de Julho de } 2017\end{array}$ \\
\hline
\end{tabular}

PASSINI, Elza Yazuco. Alfabetização cartográfica e o livro didático: uma análise crítica. Belo Horizonte: Editora Lê, 1994. 94 p.

SANTOS, N. B. F. dos.; NASCIMENTO, D. T. F.; BUENO, M. A. Atlas escolar geográfico, histórico e cultural do estado de Goiás. Goiânia: C\&A Alfa Comunicação, 2016.

SIMIELLI, M. E. R. O mapa como meio de comunicação: implicações no ensino de geografia do $1^{\circ}$ grau. Tese (Doutorado), São Paulo, FFLCH - USP, 1986. 205p. 